\title{
Microwave ablation vs. cryoablation for treatment of primary and metastatic pulmonary malignant tumors
}

\author{
HONG-WEI LI ${ }^{1 *}$, YONG-JUN LONG ${ }^{1 *}$, GAO-WU YAN $^{2 *}$, ANUP BHETUWAL $^{3}$, LI-HUA ZHUO ${ }^{1}$, \\ HONG-CHAO YAO ${ }^{1}$, JIE ZHANG ${ }^{1}$, XING-XIONG ZOU ${ }^{1}$, PEI-XI HU ${ }^{1}$, HAN-FENG YANG $^{3}$ and YONG DU ${ }^{3}$ \\ ${ }^{1}$ Department of Radiology, The Third Hospital of Mianyang, Sichuan Mental Health Center, Mianyang, Sichuan 621000; \\ ${ }^{2}$ Department of Radiology, Suining Central Hospital, Suining, Sichuan $629000 ;{ }^{3}$ Sichuan Key Laboratory of Medical Imaging \\ and Department of Radiology, Affiliated Hospital of North Sichuan Medical College, Nanchong, Sichuan 637000, P.R. China
}

Received January 31, 2021; Accepted November 24, 2021

DOI: $10.3892 / \mathrm{mco} .2022 .2495$

\begin{abstract}
At present, minimally invasive surgery is one of the primary strategies for the treatment of malignant pulmonary tumors. Although, there are some comparative studies between microwave ablation and radiofrequency for the treatment of malignant pulmonary tumors, there are few studies that have investigated the comparison between microwave ablation and cryoablation. The aim of the study was to retrospectively compare the efficacy and complications of microwave ablation (MWA) and cryoablation in the treatment of malignant pulmonary tumors. A retrospective analysis was performed on 48 patients with malignant lung tumors treated with MWA or cryoablation in The Third Hospital of Mianyang and The Affiliated Hospital of North Sichuan Medical College between June 2014 and June 2018. Of these patients, 29 received MWA and 19 received cryoablation. Intraprocedural pain was evaluated by using the visual analog scale (VAS). The intraprocedural pain, response rates, overall survival (OS) and complications rates were compared between the MWA group and cryoablation group. The results showed that the patients in the MWA group experienced more pain than those in cryoablation group as the MWA group VAS scores were much higher than those in cryoablation group $(\mathrm{P}<0.001)$. The overall response rate of the MWA group [21/29 (72.41\%)] was not significantly different from the cryoablation group [14/19 (73.68\%)] $(\mathrm{P}=0.92)$. The 6-, 12-, 24- and 36-month OS rates in the MWA group and cryoablation group were $92.72,81.28$, 64.54 and $54.91 \%$, and $94.07,81.13,57.33$ and $43.04 \%$, respectively. No significant differences were found in the OS rate
\end{abstract}

Correspondence to: Professor Gao-Wu Yan, Department of Radiology, Suining Central Hospital, 127 Desheng West Road, Suining, Sichuan 629000, P.R. China

E-mail: yangaowu1989@163.com

*Contributed equally

Key words: microwave ablation, cryoablation, pulmonary tumors, treatment between the two groups $(\mathrm{P}=0.79)$. The complication rates in the MWA and cryoablation groups were 34.48 and $36.84 \%$, respectively; there was no significant difference between the two groups $(\mathrm{P}=0.59)$. No patients died during the perioperative period. Cryoablation had a similar therapeutic effect compared with MWA in the treatment of pulmonary malignant tumors, but was associated with less pain.

\section{Introduction}

Pulmonary malignant tumors are one of the frequently occurring diseases worldwide; according to reports, the incidence rate of lung cancer is $57.63 / 100,000$, with an annual lung cancer-related mortality rate of 48.8/100,000 $(1,2)$.

With the continuous technical development of low-dose spiral computed tomography (CT), the detection rate of early lung cancer has greatly improved (3). Although surgical resection does remain the primary and preferred approach for the treatment of lung cancer, its extensive invasiveness, as well as lobectomy, can have a profound effect on pulmonary function (4). When there are contraindications to surgery (such as pulmonary dysfunction or comorbid medical conditions) or patients refuse surgical procedures, minimally invasive surgical techniques [such as radiofrequency ablation (RFA), microwave ablation (MWA) and cryoablation] can be used, which are effective, less invasive and less detrimental for pulmonary function, particularly for patients with limited pulmonary reserve (5). For early lung cancer, the primary purpose of tumor ablation therapy is to ensure eradication of all malignant cells, including a margin of normal tissue; for advanced lung cancer, the main purpose is to reduce tumor cell volume and minimize tumor burden (6). Among the ablation techniques, MWA has been used with increasing frequency in the treatment of pulmonary tumors. Percutaneous cryoablation, a relatively new ablation technique, possesses several advantageous properties, such as good visualization under CT or MRI guidance, minimal intra-procedural pain and preservation of collagenous architecture, which are conducive to application to the treatment of cancer in various non-aerated organs, such as the liver, kidney and pancreas $(7,8)$. However, studies comparing the performance of microwave ablation (MWA) vs. cryoablation in primary or metastatic pulmonary 
malignant tumors remain scarce. The aim of the present study was to compare the effectiveness and complications associated with these two methods in the treatment of pulmonary malignant tumors, and provide a basis for follow-up research that guides clinical decision making in the treatment of lung cancer.

\section{Materials and methods}

Patients and tumor criteria. In this retrospective study, the records of 48 consecutive patients (34 male patients and 14 female patients; median age, 59 years; range, $45-73$ years) who underwent MWA or cryoablation procedures for primary or metastatic pulmonary malignant tumors in The Third Hospital of Mianyang and The Affiliated Hospital of North Sichuan Medical College between June 2014 and June 2018 were reviewed. Inclusion criteria for the present study were as follows: i) Patients with a general condition where they cannot tolerate thoracotomy, such as poor lung function and elderly age; and ii) early lung cancer where there are indications for surgical resection, but patients refused surgery. The exclusion criteria were as follows: i) Tumor diameter $>5 \mathrm{~cm}$; ii) severe pulmonary dysfunction, maximum ventilation volume $<39 \%$ or poor general condition; and iii) severe bleeding diathesis. The final study group comprised of 29 patients in the MWA group and 19 patients in the cryoablation group. The baseline characteristics of the two groups prior to treatment are shown in Table I. The median preoperative Karnofsky Performance Status scale scores were $>80$. The histological distribution and tumor location of primary and secondary pulmonary malignancies are summarized in Table II. The present study was reviewed and approved by the Ethics Committee of Affiliated Hospital of North Sichuan Medical College. Written informed consent was obtained from all the patients enrolled in the study.

Ablation technique. All of the lung MWA and cryoablation were performed by using CT (Philips MX16; Koninklijke Philips N.V.) with the following parameters: section thickness, 3-6 mm; 20-40 mAs; and 120-150 kV.

MWA procedure. MWA was performed with a KY-2000 microwave multi-function therapeutic instrument (Jiangsu Kangyou Medical Instrument Co., Ltd.), which can produce $10-100 \mathrm{~W}$ (continuously adjustable) of power at a microwave frequency of 2,450 MHz. A microwave antenna (14-20 gauge, depending on tumor size and location) was inserted into the lesion.

Cryoablation procedure. A cryoablation therapeutic instrument [CryoHit argon-helium cryoablation system; AccuTarget MediPharma (Shanghai) Co., Ltd.] was used, which can reduce the needle temperature to between -120 and $-165^{\circ} \mathrm{C}$. The specifications of the argon-helium puncture needle are $14 \mathrm{G}, 16 \mathrm{G}$ and $18 \mathrm{G}$. Cryoablation was performed using a three-cycle freeze-thaw phase protocol. The freezing temperatures ranged from $-140^{\circ} \mathrm{C}$ to $-165^{\circ} \mathrm{C}$, and $20-40^{\circ} \mathrm{C}$ for thawing. The times for each phase were recorded and varied depending on the size of the tumor (target times: freeze, 3 min; thaw, $3 \mathrm{~min}$; freeze, $8 \mathrm{~min}$; thaw, $5 \mathrm{~min}$; freeze, $8 \mathrm{~min}$; followed by active thawing). For lesions $<3.0 \mathrm{~cm}$ in diameter, one antenna or cryoprobe was inserted, whereas two antennas or cryoprobes were inserted for lesions $>3.0 \mathrm{~cm}$. Each procedure was monitored using non-contrast CT imaging at intervals of 3-5 min to visualize the growing ablation zone, with the goal of achieving a circumferential margin of $0.5 \mathrm{~cm}$ beyond the tumor. If the tumor was not ablated in one session, multiple sequential ablations based on tumor size, location and geometry were performed to achieve complete necrosis.

All treatments were performed by one board-certified interventional radiologist with patients under local anesthesia (subcutaneous injection of $2 \%$ lidocaine). The patients were continuously monitored throughout the procedure with electrocardiography and pulse oximetry. Blood pressure was measured and recorded at 5-min intervals. At the end of every procedure, a CT scan was performed to identify any complications, after which the patients were transferred to the in-patient ward for 24-h observation.

Measurement of intraprocedural pain. Prior to the commencement of the procedure, the visual analog scale (VAS) was introduced to patients as a measurement of intraprocedural pain. The VAS consists of a $10-\mathrm{cm}$ line anchored at one end by a label 'no pain, score 0' and at the other end by a label 'pain as bad as can be, score 10' (9). After the procedure, the patients were instructed to report the severity of pain felt during the MWA or cryoablation procedure using the VAS.

Complication, follow-up and evaluation. Complications were recorded on a per-treatment basis and classified in accordance with the Common Terminology Criteria for Adverse Events (CTCAE) (10). Patients were followed up at the outpatient department or by contacting through telephone. Patients were reviewed by performing contrast-enhanced $\mathrm{CT}$ or positron emission tomography (PET)/CT, in addition to laboratory examination, to evaluate ablation efficacy. In both the MWA and cryoablation groups, the initial follow-up contrast-enhanced CT was generally performed monthly for the first 3 months, at 3-month intervals after that for the rest of the first year, and then annually thereafter. PET/CT was generally carried out when patients had severe iodine contrast agent allergy, or when local control and/or systemic progression needed to be evaluated. Irregular focal soft-tissue enhancement (>15 HU) or increased uptake in the PET/CT were defined as a sign of residual cancer or cancer recurrence $(11,12)$. Outcomes were evaluated according to Response Evaluation Criteria in Solid Tumors protocol (13): Lesion disappearance (scar) or $<5 \%$ of original size is defined as complete response (CR); partial response (PR) is $\geq 30 \%$ decrease; stable disease (SD) exhibits no change; and progressive disease (PD) is $\geq 20 \%$ increase in the sum of the longest diameter of the target lesion. Postoperative complications were followed up by CT scan at 1 month after the ablation. Telephone follow-up mainly enquired about symptoms, quality of life and survival.

Statistical analysis. All of the data processing was performed with SPSS statistical software 23.0 (IBM Corp.). Measurement and numeration data were analyzed using the $\chi^{2}$ test and unpaired t-test, respectively, to compare the two groups. VAS scores were assessed using a Mann-Whitney test. Fisher's 
Table I. Comparison of baseline characteristics between the two groups of patients.

\begin{tabular}{|c|c|c|c|}
\hline Baseline characteristic & Microwave ablation & Cryoablation & P-value \\
\hline Patients, $\mathrm{n}$ & 29 & 19 & \\
\hline Age, years & $58.48 \pm 7.86$ & $60.95 \pm 7.45$ & 0.28 \\
\hline Sex, n & & & 0.77 \\
\hline Male & 21 & 13 & \\
\hline Female & 8 & 6 & \\
\hline KPS score & $87.35 \pm 4.09$ & $87.42 \pm 3.31$ & 0.94 \\
\hline Tumor type, $\mathrm{n}$ & & & 0.50 \\
\hline Primary & 21 & 12 & \\
\hline Metastasis & 8 & 7 & \\
\hline Tumor size, $\mathrm{cm}$ & $2.43 \pm 0.71$ & $2.01 \pm 0.53$ & 0.03 \\
\hline$<3 \mathrm{~cm}$ & $2.11 \pm 0.37$ & $1.88 \pm 0.39$ & 0.72 \\
\hline$\geq 3 \mathrm{~cm}$ & $3.46 \pm 0.52$ & $3.1 \pm 0.14$ & 0.39 \\
\hline UICC stage, $\mathrm{n}$ & & & 0.97 \\
\hline $\mathrm{I}+\mathrm{II}$ & 20 & 13 & \\
\hline III + IV & 9 & 6 & \\
\hline Ablation session, $\mathrm{n}$ & & & 0.92 \\
\hline 1 & 21 & 14 & \\
\hline$\geq 2$ & 8 & 5 & \\
\hline Combined with chemotherapy, n & & & 0.87 \\
\hline Yes & 21 & 15 & \\
\hline No & 8 & 4 & \\
\hline Combined with radiation therapy, $\mathrm{n}$ & & & 0.98 \\
\hline Yes & 6 & 4 & \\
\hline No & 23 & 15 & \\
\hline Combined with surgical resection, $\mathrm{n}$ & & & 0.65 \\
\hline Yes & 6 & 5 & \\
\hline No & 23 & 14 & \\
\hline
\end{tabular}

KPS, Karnofsky performance status; UICC, Union for International Cancer Control.

exact test was used when expected number of cases was $\leq 5$. The $\chi^{2}$ or Fisher's exact test was used to analyze the CR, PR, $\mathrm{SD}$ and $\mathrm{PD}$ of the two groups. Overall survival (OS) rates were estimated according to the life-table method. Kaplan-Meier survival analyses was used to calculate survival curves at 6 , 12, 24 and 36 months after MWA and cryoablation. $\mathrm{P}<0.05$ was considered to indicate a statistically significant difference.

\section{Results}

Intraprocedural pain, and short- and long-term efficacy evaluation. The patients in the MWA group reported more pain than those in cryoablation group; the VAS scores in the MWA group were significantly increased compared with those in the cryoablation group $(\mathrm{P}<0.001$; Table III). The short-term efficacy rates $(\mathrm{CR}+\mathrm{PR})$ in the MWA and cryoablation groups were $72.41 \%(21 / 29)$ and $73.68 \%(14 / 19)$, respectively (Figs. 1 and 2 and Table IV); there was no statistically significant difference for the short-term efficacy rates between the two groups $(\mathrm{P}=0.92)$. For long-term evaluation, six patients the in MWA group and five patients in the cryoablation group were lost to follow-up, leaving 23 patients in the MWA group and 14 patients in the cryoablation group available for long-term efficacy analysis. The 6-, 12-, 24-, 36-month OS rates in the MWA and cryoablation groups were $92.72,81.28,64.54$ and $54.91 \%$, and 94.07, 81.13, 57.33 and $43.04 \%$, respectively. No significant differences were observed for OS between the two groups ( $\mathrm{P}=0.79$; Fig. 3). In addition, in the MWA group, one $(3.45 \%)$ patient exhibited disease progression at ablative sites, whereas in the cryoablation group, one $(5.26 \%)$ patient exhibited disease progression at ablative sites, which was statistically insignificant $(\mathrm{P}=0.64)$. Regarding disease progression distant from the ablation site, in the MWA group, six $(20.69 \%)$ patients developed metastases in lobes other than at the ablative sites or distant sites after 3 years of follow-up, whereas in the cryoablation group, $4(21.05 \%)$ patients developed metastases in lobes other than at the ablative sites or distant sites.

Follow-up and postoperative complications. In the two groups of patients, all ablation sessions were successfully completed and all pulmonary malignant tumors were ablated. 
Table II. Histological distribution and tumor location of pulmonary malignant tumors.

\begin{tabular}{lcc}
\hline Criterion & Microwave ablation, $n(\%)$ & Cryoablation, n $(\%)$ \\
\hline Tumor type & $21(72.41)$ & $12(63.16)$ \\
Primary (NSCLC) & $8(27.59)$ & $7(34.84)$ \\
Secondary & & $3(15.79)$ \\
Primary tumor (NSCLC) type & $4(13.79)$ & $9(47.36)$ \\
Squamous carcinoma & $17(58.62)$ & $4(21.05)$ \\
Adenocarcinoma & & $0(0)$ \\
Secondary tumor & $3(10.34)$ & $2(10.53)$ \\
Colorectal & $2(6.70)$ & $1(5.26)$ \\
Hepatocellular & $2(6.70)$ & \\
Breast & $1(3.45)$ & $3(15.79)$ \\
Renal cell carcinoma & & $16(84.21)$ \\
Tumor location & $5(17.24)$ & 0.69 \\
Central & $24(82.76)$ & 0.90 \\
Peripheral & & \\
\hline
\end{tabular}

NSCLC, non-small cell lung cancer.

Table III. Results of intraprocedural pain evaluation.

\begin{tabular}{lcc}
\hline Variable & Microwave ablation $(\mathrm{n}=29)$ & Cryoablation $(\mathrm{n}=19)$ \\
\hline VAS, median (interquartile range) & $5(4,8)$ & $3(1,5)$
\end{tabular}

VAS, visual analogue scale.

Complications were recorded on a per-treatment basis and classified in accordance with the Common Terminology Criteria for Adverse Events (CTCAE) (10). There were no intraprocedural deaths. Out of 48 patients, 37 were followed up until the completion of the study (23 cases from the MWA group and 14 from the cryoablation group), with 11 patients lost to follow-up. The follow-up period was 6-48 months, and the mean follow-up period was 22.3 months. The frequency of procedure-related complications after ablation is reported in Table $\mathrm{V}$.

The mean operation time was $36 \mathrm{~min}$ (range, 30-63 min) in the MWA group and $53 \mathrm{~min}$ (range, $42-78 \mathrm{~min}$ ) in the cryoablation group, which was significantly different between the two group $(\mathrm{P}<0.001)$. In the MWA group, the mean post-operative hospital stay was 6.7 days (range, 1-22 days). In total, one case was treated with closed drainage of pleural cavity, and sixteen cases were treated with hemostatic drugs or similar conservative treatments without surgical interference, which were recovered within one month. The remaining four patients exhibited a longer postoperative hospital stay (mean, 15.5 days; range, 11-22 days) due to co-morbidities, such as chronic bronchitis, emphysema or heart failure. In the cryoablation group, the mean postoperative hospital stay was 7.1 days (range, 3-26 days). A total of 16 cases treated with hemostatic drugs or morphine recovered within 3-8 days; the remaining three patients exhibited a longer postoperative hospital stay (mean, 17 days; range, 10-26 days) due to co-morbidities. However, there was no significant difference in postoperative hospital stay.

In the MWA group, the total incidence of pneumothorax was $10.3 \%$ (3/29); two cases (CTCAE grade 1) were treated conservatively without interference, and one case (CTCAE grade 2) was managed with closed drainage of the pleural cavity. Intraparenchymal pulmonary hemorrhage (CTCAE grade 1) was detected in $13.8 \%$ (4/29) of cases, which was self-limiting. Additionally, two cases of hemoptysis and one case of pleural effusion were detected, with complete spontaneous resolution within 1 month. In the cryoablation group, the total incidence of pneumothorax was $10.5 \%$ (2/19), which was self-limiting. Intraparenchymal pulmonary hemorrhage (CTCAE grade 1) developed in $15.6 \%$ (3/19) of cases, with complete resolution within 1 month. Finally, one case of hemoptysis and one case of pleural effusion were found and treated without interference. There was no statistically significant difference in the incidence of complications between the two groups $(\mathrm{P}=0.59)$.

\section{Discussion}

Image-guided percutaneous ablation in the treatment of primary or metastatic malignant tumors has been increasingly used, which has the advantages of reproducibility, good 
A

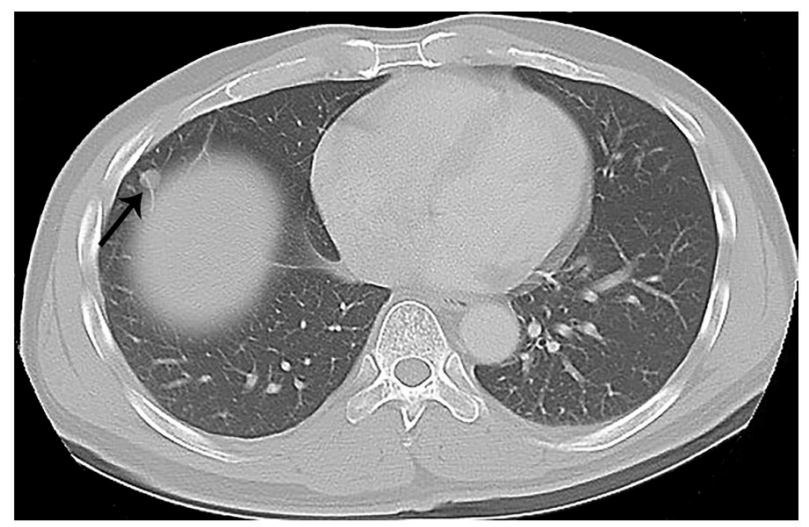

B

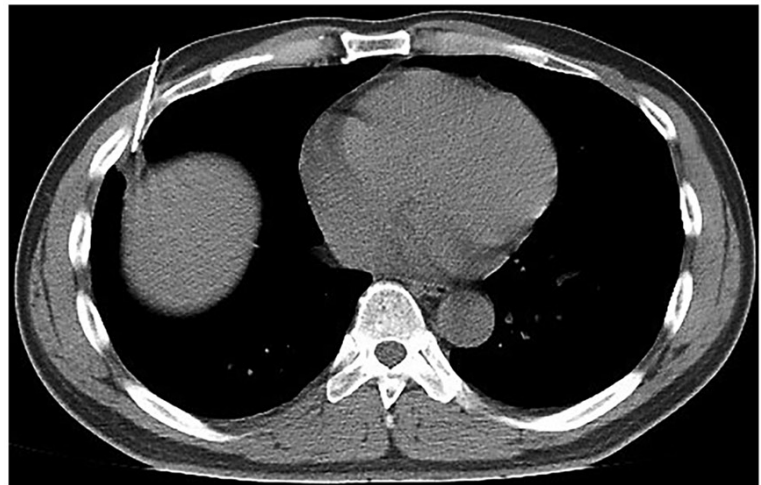

C

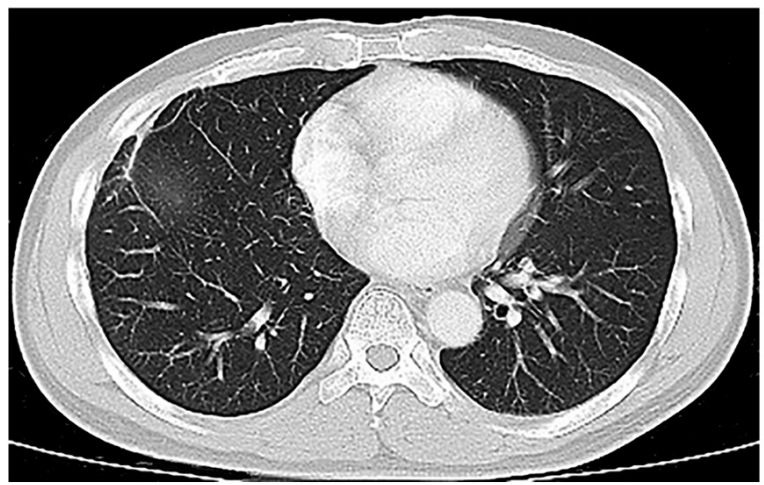

D

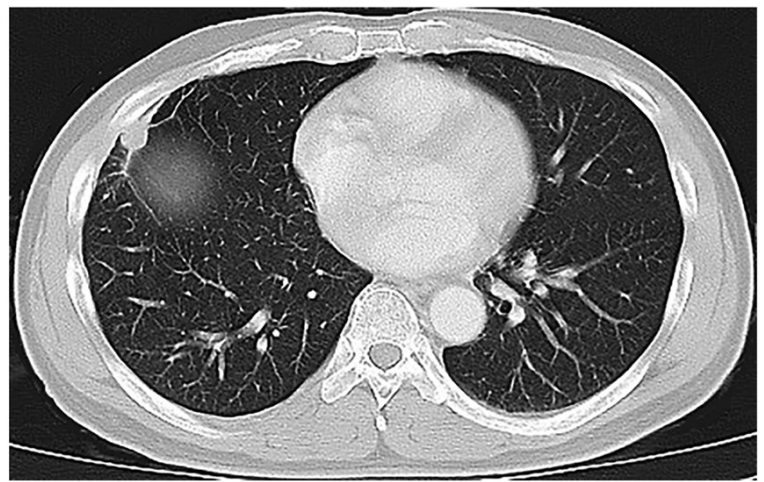

Figure 1. Cryoablation of a pulmonary metastasis after lung cancer resection (A) CT scan shows that the tumor was located in the anterior basal segment of the right lower lobe (diameter, $0.8 \mathrm{~cm}$ ), which is adjacent to the diaphragm (arrow). (B) CT scan obtained during the cryoablation procedure shows the tip of ablation needle; the ablation margin was $1.9 \mathrm{~cm}$. (C) CT scan obtained at 3 months after ablation indicates the lesion contracted into a fibrotic scar (D) CT scan obtained with contrast enhancement at 8 months shows tumor recurrence within the ablation zone. CT, computed tomography.

efficacy, low cost and less trauma (14). At present, percutaneous ablation under CT guidance has been effectively implemented
Table IV. Results of short-term efficacy evaluation

\begin{tabular}{lcc}
\hline Outcome & $\begin{array}{c}\text { Microwave } \\
\text { ablation, n }(\%)\end{array}$ & $\begin{array}{c}\text { Cryoablation, } \\
\mathrm{n}(\%)\end{array}$ \\
\hline Complete response & $10 / 29(34.48)$ & $7 / 19(36.84)$ \\
Partial response & $11 / 29(37.93)$ & $7 / 19(36.84)$ \\
Stable disease & $7 / 29(24.14)$ & $4 / 19(21.05)$ \\
Progressive disease & $1 / 29(3.45)$ & $1 / 19(5.26)$ \\
Overall response & $21 / 29(72.41)$ & $14 / 19(73.68)$
\end{tabular}

in patients with primary or metastatic pulmonary malignant tumors who are medically inoperable or refuse surgery (15).

MWA is increasingly used to treat stage I non-small cell lung carcinoma (NSCLC), metastatic lung cancer and advanced lung cancer combined with radiotherapy and chemotherapy. Yao et al (16) compared results of 54 patients with stage I NSCLC undergoing MWA with that of 795 patients with stage I NSCLC undergoing lobectomy, and concluded MWA has a similar therapeutic effect compared with lobectomy for stage I NSCLC, but with fewer complications and less pain. Yang et al (17) retrospectively analyzed the local recurrence and repeatability of MWA in 104 patients with stage I NSCLC and concluded that the local recurrence rate was lower in tumors $\leq 3.5 \mathrm{~cm}$ compared with tumors $>3.5 \mathrm{~cm}$. The same study reported that compared with patients without local recurrence, using MWA repeatedly can achieve a similar OS and progression-free survival, but without additional complications. In addition, the study also found that high-frequency ablations exhibited larger ablation margins and reduced local progression compared with low-frequency ablations (18). In conclusion, a number of studies have shown that the use of MWA in the treatment of stage I/II NSCLC and metastatic nodules is safe and effective.

Although numerous studies have investigated MWA, there are only a small number of studies focusing on cryoablation for lung malignant tumors. The mechanism of cryoablation includes intracellular ice crystal formation, disruption of organelles and cell membranes, vascular stasis and microvascular thrombosis, which lead to cell death $(19,20)$. Kawamura et al (21) reported the results of 22 cryoablation sessions in 20 patients with 35 pulmonary metastases and found that there was local recurrence of seven $(20 \%)$ tumors in seven (35\%) patients during a 9- to 28-month (median, 21 months) follow-up period, with a 1-year survival rate of $89.4 \%$. Another study of 117 patients with 193 tumors treated with cryoablation also suggested that percutaneous cryoablation could be performed with minimal invasion and acceptable rates of complications (22). Furthermore, in a retrospective study of cryoablation using thin needles for 34 pulmonary tumors (11 NSCLC, 23 metastases), technical success (complete lack of enhancement) was achieved in 82,97 and $91 \%$ of treated lesions at the 1-, 3- and 6-month CT follow-ups (23). These studies demonstrated that percutaneous cryoablation of lung tumors treatment is effective, minimally invasive and safe with satisfactory local control.

In addition, Li et al (24) suggested that cryoablation not only leads to destruction of targeted cells directly, but also 
A

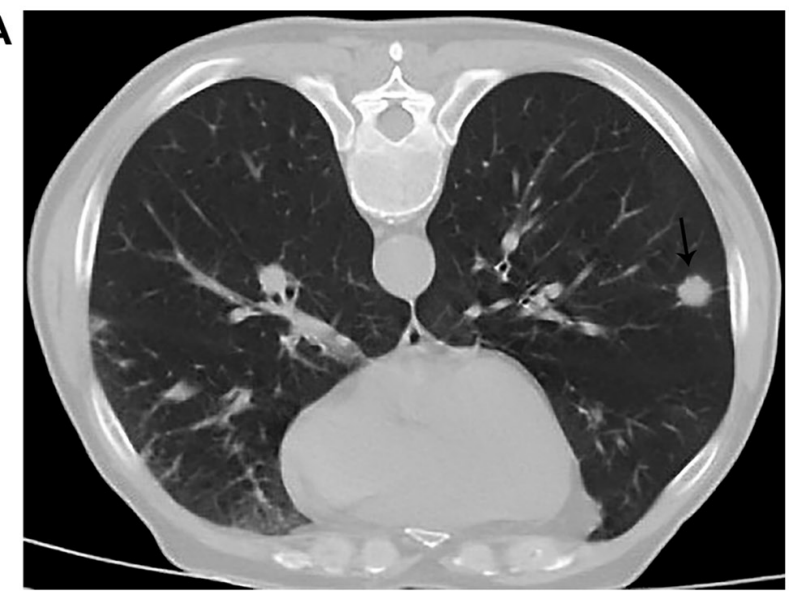

\section{B}

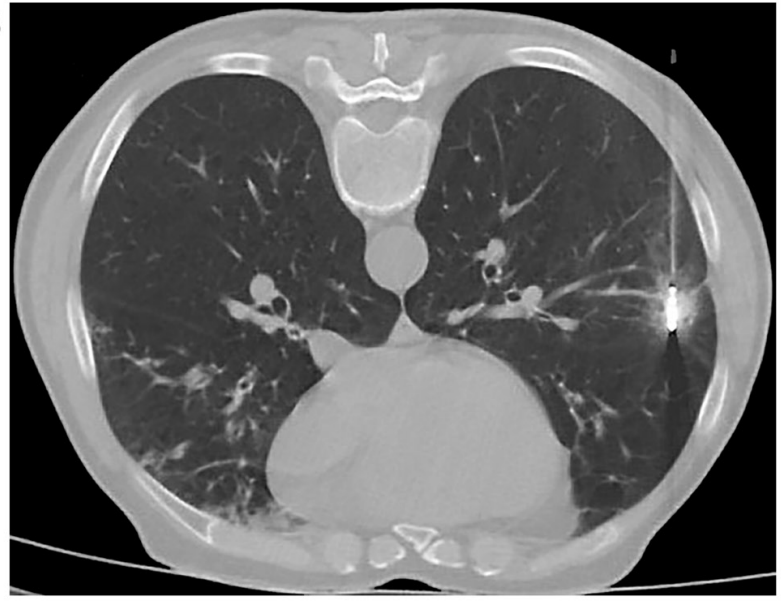

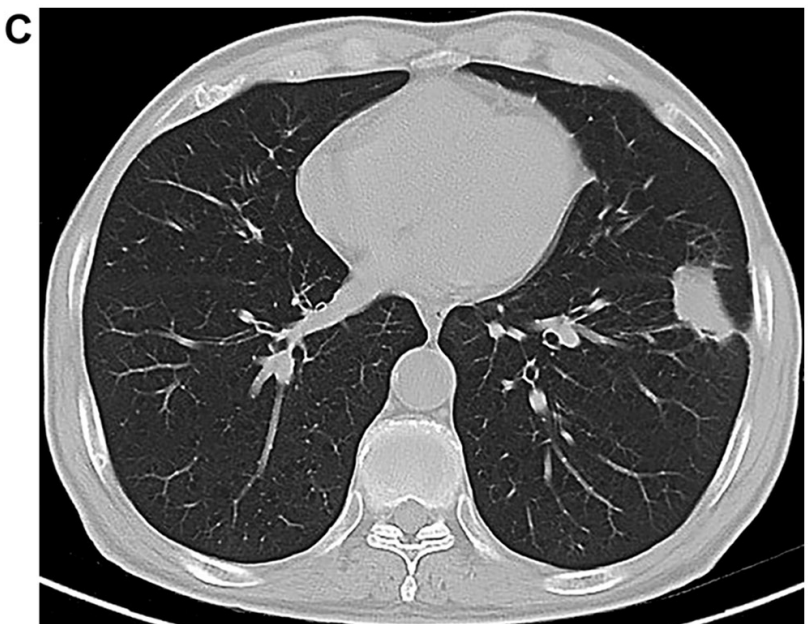

D

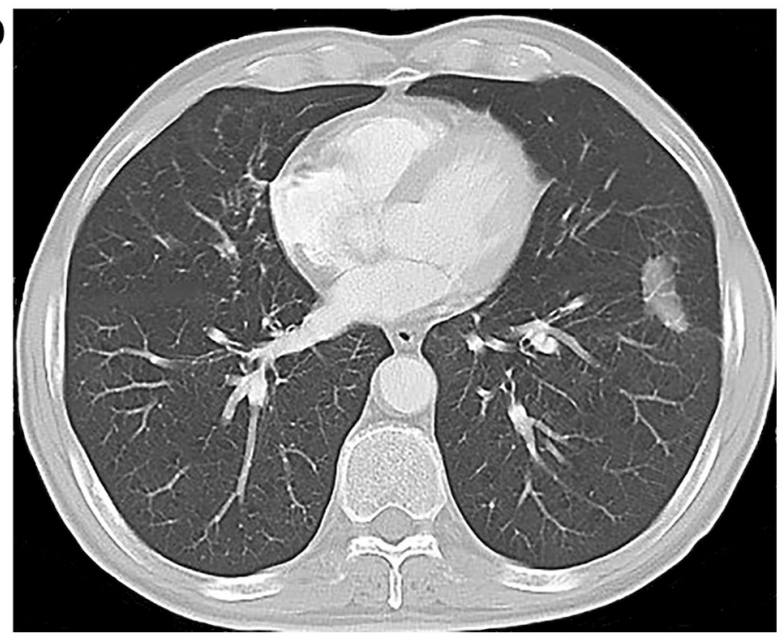

Figure 2. Microwave ablation of a primary pulmonary malignant tumor. (A) CT scan shows that the tumor was located in the anterior basal segment of the right lower lobe (diameter, $1.7 \mathrm{~cm}$ ), which is in direct contact with two small blood vessels (arrow). (B) CT scan obtained during microwave ablation procedure shows the tip of ablation needle; the ablation margin was $2.3 \mathrm{~cm}$. (C) Contrast-enhanced CT scan obtained at 2 months indicates that the lesion size increased but with lack of enhancement. (D) Contrast-enhanced CT scan at 5 months shows tumor volumetric reduction and had lack of enhancement. CT, computed tomography.

results in reduced release of immunosuppressive factors from tumor cells and enhanced antitumor immune response, which plays an important role in eliminating the residual tumor cells and inhibiting the growth of local tumors.

The present study indicated that the patients from the MWA group experienced more pain compared with those in the cryoablation group, with significantly higher VAS scores, which is in line with the findings of Das et al (25). There were no statistically significant differences between the two groups in terms of short-term efficacy and OS rates. Das et al (25) previously demonstrated that MWA and cryoablation procedures were comparably effective treatment modalities with similar survival benefits in patients with advanced NSCLC with small tumors.

At present, there are various comparative studies of MWA and radiofrequency for the treatment of malignant tumors of the lung, but there are few studies comparing MWA and cryoablation. Compared with RFA, MWA is considered to achieve more homogenous heating, higher tissue temperatures, larger ablation volumes and less heat sink effect, resulting in reduced treatment time and an improved convection profile $(26,27)$. However, initial microwave systems suffered from poor antenna design, inability to create spherical ablation zones and concerns regarding remote conduction of energy $(28,29)$. Additionally, the range of MWA is not easy to control, which can inadvertently injure adjacent organs. Cryoablation has certain advantages, including good visualization under CT or MRI guidance, low intraprocedural pain and preservation of collagenous architecture, which are conducive to application in the treatment of cancer in various non-aerated organs $(7,8)$. However, in comparison with microwave probes, the cryoprobes are larger and have a blunt tip, which leads to substantial difficulties for percutaneous cryoablation of lung tumors.

Therefore, both MWA and cryoablation can be used to treat the majority of primary or metastatic pulmonary malignant tumors. MWA therapy could be a therapeutic option when the tumors are relatively large and far away from the large blood vessels and other important organs. For tumors that are relatively small $(<3 \mathrm{~cm})$ and adjacent to blood vessels or important organs, and in patients who cannot endure pain, cryoablation is considered to be a preferred approach (30). In addition, for patients with non-resectable advanced malignant tumors, both ablation therapies can substantially alleviate tumor burden, reduce breathing impairments in patients with borderline lung function and improve the effect of comprehensive treatment $(29,31)$. 
Table V. Frequency of procedure-related complications after ablation.

\begin{tabular}{lcc}
\hline Procedure-related complication & Microwave ablation, n $(\%)$ & Cryoablation, n $(\%)$ \\
\hline Pneumothorax & $3 / 29(10.34)$ & $2 / 19(10.53)$ \\
Pulmonary hemorrhage & $4 / 29(13.79)$ & $3 / 19(15.79)$ \\
Hemoptysis & $2 / 29(6.90)$ & $1 / 19(5.26)$ \\
Pleural effusion & $1 / 29(3.45)$ & $1 / 19(5.26)$ \\
All complications & $10 / 29(34.48)$ & $7 / 19(36.84)$
\end{tabular}

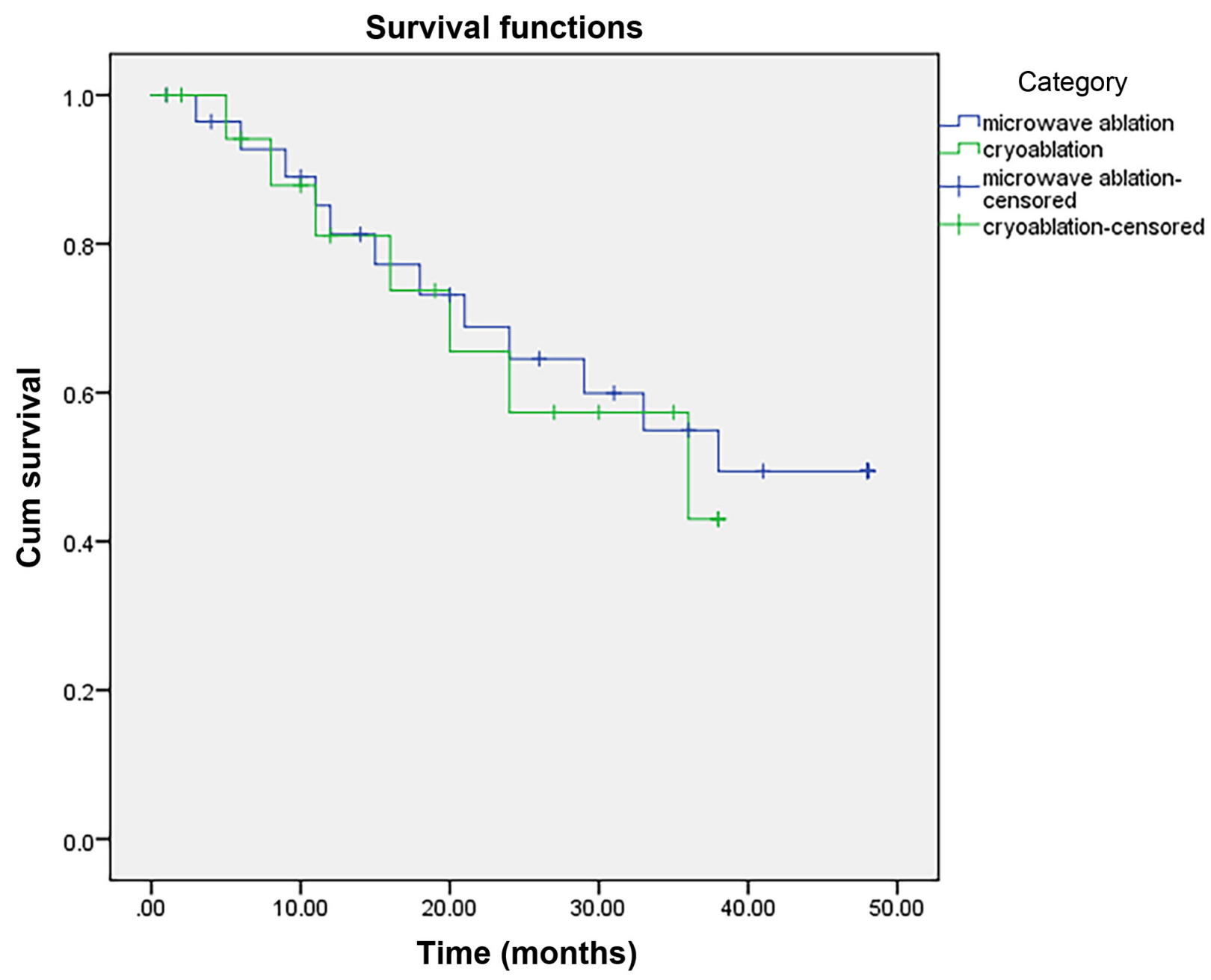

Figure 3. Kaplan-Meier analysis of overall survival rates of patients with pulmonary tumors treated by microwave ablation or cryoablation.

The current study is limited by a number of factors, including a non-randomized, non-controlled retrospective design, relatively small sample size and the element of bias in the selection of the modality used for ablation. Furthermore, the analysis of this study did not consider effects before or after radiotherapy, chemotherapy or other systemic treatment.

In conclusion, the present study reported a comparison of two ablation modalities in the treatment of lung malignant tumors. According to the study findings, cryoablation exhibited a similar therapeutic efficacy compared with MWA in the treatment of pulmonary malignant tumors, but with reduced pain. Therefore, the preferred approach should be determined primarily based on pre-ablation tumor size, location in relation to the important organs and pain tolerance of the patients.

\section{Acknowledgements}

The authors would like to thank Dr Morgan A McClure (Department of Radiology, Nanchong Central Hospital, Sichuan, China) for helping to polish the grammar and structure of the manuscript.

\section{Funding}

No funding was received. 


\section{Availability of data and materials}

The datasets generated and/or analyzed during the current study are available from the corresponding author on reasonable request.

\section{Authors' contributions}

HWL, YJL, YD and GWY contributed to the study conception and design. LHZ, HCY, JZ, XXZ, PXH, HFY and AB contributed to the literature search, data collection, statistical analysis and data interpretation. YD and $\mathrm{AB}$ revised the manuscript. HWL, YD and GWY confirm the authenticity of all the raw data. All authors have read and approved the final manuscript.

\section{Ethics approval and consent to participate}

The present study was reviewed and approved by the Ethics Committee of Affiliated Hospital of North Sichuan Medical College (approval no. 202016). Written informed consent was obtained from all the patients enrolled in the study.

\section{Patient consent for publication}

Not applicable.

\section{Competing interests}

The authors declare that they have no competing interests.

\section{Authors' information}

HWL-ORCID ID: 0000-0003-0083-8279; YJL-ORCID ID: 0000-0003-4930-6716; LHZ-ORCID ID: 0000-00019986-9045; HCY-ORCID ID: 0000-0001-9099-4886; JZ-ORCID ID: 0000-0002-9507-7013; XXZ-ORCID ID: 0000-0002-9801-1909; PXH-ORCID ID: 0000-00031408-8114; AB-ORCID ID: 0000-0002-4782-3018; HFY-ORCID ID: 0000-0001-5156-2984; YD-ORCID ID: 0000-0002-8119-3195.

\section{References}

1. Torre LA, Bray F, Siegel RL, Ferlay J, Lortet-Tieulent J and Jemal A: Global cancer statistics, 2012. CA Cancer J Clin 65: 87-108, 2015.

2. Ferlay J, Soerjomataram I, Dikshit R, Eser S, Mathers C, Rebelo M, Parkin DM, Forman D and Bray F: Cancer incidence and mortality worldwide: Sources, methods and major patterns in GLOBOCAN 2012. Int J Cancer 136: E359-E386, 2015.

3. Oudkerk M, Liu S, Heuvelmans MA, Walter JE and Field JK: Lung cancer LDCT screening and mortality reduction-evidence, pitfalls and future perspectives. Nat Rev Clin Oncol 18: 135-151, 2021

4. Nomori H, Yamazaki I, Machida Y, Otsuki A, Cong Y, Sugimura H and Oyama Y: Lobectomy versus segmentectomy: A propensity score-matched comparison of postoperative complications, pulmonary function and prognosis. Interact Cardiovasc Thorac Surg 25: ivab212, 2021.

5. Akalin A, Mu X, Kon MA, Ergin A, Remiszewski SH, Thompson CM, Raz DJ, Diem M, Bird B and Miljković M: Classification of malignant and benign tumors of the lung by infrared spectral histopathology (SHP). Lab Invest 95: 697, 2015.

6. Du S, Qin D, Pang R, Zhang Y, Zhao S, Hu M and Zhi X: Long-term efficacy of radiofrequency ablation combined with chemotherapy in the treatment of patients with advanced non-small cell lung cancer-a retrospective study. Zhongguo Fei Ai Za Zhi 20: 675-682, 2017 (In Chinese).
7. Sonntag PD, Hinshaw JL, Lubner MG, Brace CL and Lee FT Jr: Termal ablation of lung tumors. Surg Oncol Clin N Am 20: 369-387, 2011.

8. Erinjeri JP and Clark TW: Cryoablation: Mechanism of action and devices. J Vasc Interv Radiol 21 (8 Suppl): S187-S191, 2010.

9. Lee S, Rhim H, Kim YS, Choi D, Lee WJ, Lim HK and Shin B: Percutaneous radiofrequency ablation of hepatocellular carcinomas: Factors related to intraprocedural and postprocedural pain. AJR Am J Roentgenol 192: 1064-1070, 2009.

10. Dueck AC, Mendoza TR, Mitchell SA, Reeve BB, Castro KM, Rogak LJ, Atkinson TM, Bennett AV, Denicoff AM, O'Mara AM, et al: National cancer institute PRO-CTCAE study group. Validity and reliability of the US National cancer institute's patient-reported outcomes version of the common terminology criteria for adverse events (PRO-CTCAE). JAMA Oncol 1: 1051-1059, 2015.

11. Ahmed M, Technology Assessment Committee of the Society of Interventional Radiology: Image-guided tumor ablation: Standardization of terminology and reporting criteria-a 10-year update: supplement to the consensus document. J Vasc Interv Radiol 25: 1706-1708, 2014.

12. Bojarski JD, Dupuy DE and Mayo-Smith WW: CT imaging findings of pulmonary neoplasms after treatment with radiofrequency ablation: Results in 32 tumors. AJR Am J Roentgenol 185: 466-471, 2005

13. Tsuchida Y and Therasse P: Response evaluation criteria in solid tumors (RECIST): New guidelines. Med Pediatr Oncol 37: 1-3, 2001.

14. Dupuy DE: Image-guided thermal ablation of lung malignancies. Radiology 260: 633-655, 2011.

15. Howington JA, Blum MG, Chang AC, Balekian AA and Murthy SC: Treatment of stage I and II non-small cell lung cancer: Diagnosis and management of lung cancer, 3rd ed: American College of chest physicians evidence-based clinical practice guidelines. Chest 143 (5 Suppl): e278S-e313S, 2013.

16. Yao W, Lu M, Fan W, Huang J, Gu Y, Gao F, Wang Y, Li J and Zhu Z: Comparison between microwave ablation and lobectomy for stage I non-small cell lung cancer: A propensity score analysis. Int J Hyperthermia 34: 1329-1336, 2018.

17. Yang X, Ye X, Huang G, Han X, Wang J, Li W, Wei Z and Meng M: Repeated percutaneous microwave ablation for local recurrence of inoperable Stage I nonsmall cell lung cancer. J Cancer Res Ther 13: 683-688, 2017.

18. Vogl TJ, Roman A, Nour-Eldin NA, Hohenforst-Schmidt W, Bednarova I and Kaltenbach B: A comparison between $915 \mathrm{MHz}$ and $2450 \mathrm{MHz}$ microwave ablation systems for the treatment of small diameter lung metastases. Diagn Interv Radiol 24: 31-37, 2018.

19. Gage AA and Baust J: Mechanisms of tissue injury in cryosurgery. Cryobiology 37: 171-186, 1998.

20. Hoffmann NE and Bischof JC: The cryobiology of cryosurgical injury. Urology 60 (2 Suppl 1): S40-S49, 2002.

21. Kawamura M, Izumi Y, Tsukada N, Asakura K, Sugiura H, Yashiro H, Nakano K, Nakatsuka S, Kuribayashi S and Kobayashi K: Percutaneous cryoablation of small pulmonary malignant tumors under computed tomographic guidance with local anesthesia for nonsurgical candidates. J Thorac Cardiovasc Surg 131: 1007-1013, 2006.

22. Inoue M, Nakatsuka S, Yashiro H, Ito N, Izumi Y, Yamauchi Y, Hashimoto K, Asakura K, Tsukada N, Kawamura M, et al: Percutaneous cryoablation of lung tumors: Feasibility and safety. J Vasc Interv Radiol 23: 295-302, 2012.

23. Pusceddu C, Sotgia B, Fele RM and Melis L: CT-guided thin needles percutaneous cryoablation (PCA) in patients with primary and secondary lung tumors: A preliminary experience. Eur J Radiol 82: e246-e253, 2013.

24. Li M, Liu J, Zhang SZ, Zhou Y, Guo YW, Chen Q, Ke YQ, Jiang XD and Cai YQ: Cellular immunologic response to primary cryoablation of C6 gliomas in rats. Technol Cancer Res Treat 10: 95-100, 2011.

25. Das SK, Huang YY, Li B, Yu XX, Xiao RH and Yang HF: Comparing cryoablation and microwave ablation for the treatment of patients with stage IIIB/IV non-small cell lung cancer. Oncol Lett 19: 1031-1041, 2020.

26. Martin RC, Scoggins CR and McMasters KM: Microwave hepatic ablation: Initial experience of safety and efficacy. J Surg Oncol 96: 481-486, 2007.

27. Wright AS, Lee FT Jr and Mahvi DM: Hepatic microwave ablation with multiple antennae results in synergistically larger zones of coagulation necrosis. Ann Surg Oncol 3: 275-283, 2003. 
28. Berber E: Laparoscopic microwave thermosphere ablation of malignant liver tumors: An initial clinical evaluation. Surg Endosc 30: 692-698, 2016.

29. Ma Y, Wallace AN, Waqar SN, Morgensztern D, Madaelil TP, Tomasian A and Jennings JW: Percutaneous image-guided ablation in the treatment of osseousmetastases from non-small cell lung cancer. Cardiovasc Intervent Radiol 41: 726-733, 2018

30. Wei YT and Xiao YY: Expert consensus for image-guided cryoblation of lung cancer (In Chinese). Chin J Interv Imaging Ther 15: 259-263, 2018.
31. Yashiro H, Nakatsuka S, Inoue M, Kawamura M, Tsukada N, Asakura K, Yamauchi Y, Hashimoto K and Kuribayashi S: Factors affecting local progression after percutaneous cryoablation of lung tumors. J Vasc Interv Radiol 24: 813-821, 2013.

(i) $\Theta \Theta$ This work is licensed under a Creative Commons EY NC ND Attribution-NonCommercial-NoDerivatives 4.0 International (CC BY-NC-ND 4.0) License. 